\title{
Passive UHF RFID Tags with Specific Printed Antennas for Dielectric and Metallic Objects Applications
}

\author{
Katherine SIAKAVARA, Sotirios GOUDOS, Argiris THEOPOULOS, John SAHALOS \\ Dept. of Physics, Aristotle University of Thessaloniki, 54124 Thessaloniki, Greece \\ skv@auth.gr, ssoti@physics.auth.gr, atheo@physics.auth.gr, sahalos@auth.gr \\ Submitted November 27, 2016 / Accepted July 15, 2017
}

\begin{abstract}
Design process and respective results for the synthesis of specific Radiofrequency Identification (RFID) tag antennas, suitable for dielectric and metallic objects, are presented. The antennas were designed for the UHF (865 MHz-869 MHz) band and their basic configuration is that of the printed spiral type. Six modification steps to the classical spiral layout are proposed and it was proved that they can lead to tags with high readability and reading distances up to $10 \mathrm{~m}$ when designed for dielectric object and up to $7 \mathrm{~m}$ in the case of metallic objects. The results of the measurements of the fabricated tags are explained via theoretical evaluations which take into account reflection phenomena, which are present in a real environment at which the tags are used.
\end{abstract}

\section{Keywords}

Printed antennas, RFID tags, spiral antennas

\section{Introduction}

The concept of communicating by means of reflected electromagnetic power is not new as can be traced back to more than six decades of years. Over this time period, the idea has evolved and been realized as modern, efficient and thus worldwide applied technology which exploits the capability of receiving and storing data by RF modulated and backscattered waves and in this way providing automatic wireless identification and tracking capability of things and personnel. Nowadays, applications of RFID systems span from inventory tracking, security and ticketing to electronic payment. Frequencies inside various bands of electromagnetic spectrum as the Low Frequency (LF) band, the High Frequency (HF), the Ultra High Frequency (UHF) and Microwave Frequency (MW) $(2.4 \mathrm{GHz}$ to $2.4835 \mathrm{GHz}$ and $5.8 \mathrm{GHz}$ ) bands are dedicated to RFID applications. Among these, the UHF band is preferred for most of applications since UHF passive tags are capable of offering relatively fast reading speeds and can be read over long distances [1], [2].

The main grades of an RFID system are: a) the reader (interrogator) supplied with an antenna, b) the tags (tran- sponders) which are microchips combined with an antenna in a compact package, c) a host computer, and d) a middleware including software and data base. Concisely, a passive RFID system operates in the following way: RFID reader transmits a modulated RF signal towards the RFID tag. The chip receives power from the tag's antenna and responds by varying its input impedance modulating, in this way, the backscattered signal. Modulation type, often used in RFIDs, is Amplitude Shift Keying (ASK). At ASK the chip impedance switches between two states: at the one of them it is matched to the antenna (chip collects power in that state) and at the other one it is strongly mismatched, backscattering the incident power [1], [3].

Basic requirement of the RFID forward-backward communication, is the ensuring of sufficient power at the input of the tag's IC in order that the IC to work. Two are the key factors for this to be obtained. The first one is the use of a suitable antenna capable of gathering satisfactory amount of power from the environment, as at a passive tag its antenna is the sole source of energy for the chip. The second key is the transfer of a high, as possible, fraction of this power to the IC [4]. The power selected via the tag's antenna depends inversely from the distance between reader and tag, the antenna's directive gain and these parameters along with the IC's sensitivity determine the maximum permitted distance between reader and tag at which the tag can be read. So, the designer of a tag has to solve two main problems: To design an antenna small in size but with high gain and to match the antenna to the IC. The majority of the commercial chips have complex input impedance with small real part and imaginary part of high capacitive value. Consequently in order the conjugate matching between antenna and IC to be obtained, the antenna has to operate out of resonance having an inductive input reactance. These specific requirements make the antenna's design and generally of the whole tag not an easy task.

In accordance to the literature, various configurations have been employed for the design of passive tag antennas, which aim at both satisfactory gain and matching to the IC be achieved: antennas, of simple dipole or monopole type [5], [6], of meandered line shape [7-10], of fractal shape [11-14], of metamaterial-inspired type [15-17] or based on 
Split Ring Resonator (SRR) concept [18]. Recently, published works for RFID tag antenna design propose coupled shorted patches, configured as step-impedance sections and being suitable for dielectric and metallic hosts [19]. Coupled shorted patches textured by comb-notches for efficient matching to the IC and utilization as an on-body sensors have been also proposed in [20]. Articles [21-25] suggest antennas of spiral shape which are properly modified via optimization techniques, for the required specifications of matching and gain levels to be obtained.

The target of the present work was the synthesis of passive tag antennas operating in the European RFID UHF band of $865 \mathrm{MHz}-869 \mathrm{MHz}$, with maximum, as possible, reading distance being suitable for application at dielectric and metallic objects. For the design, the spiral shape was adopted and ICs with power threshold of $-18 \mathrm{dBm}$ were considered. The design focuses not only to the matching condition between the antenna and the chip but mainly to the maximization of the gain and the distribution of the maximum gain values inside a wide space range around the tag, thus ensuring high readability, independently of the orientation of the tag with respect to the reader's antenna. These being the targets, the novel contribution of the work was the way by which the classical spiral shape of the printed antenna would be modified and the additional elements that would potentially be incorporated, to the desired performance be obtained.

The rest of the article's content is divided in three sections. In Sec. 2 the process of the tag antenna's design and the power budget of the RFID link are analytically presented. Section 3 includes the presentation of the designed tags for dielectric and metallic objects. Analytical information about their structure is given, and their records and effectiveness are shown via results received by simulation and measurements. Comparison of the designed and fabricated tags' performance with commercial tags or other ones found in the literature is also made. Section 4 includes the general conclusions.

\section{Proposed Design and Link Budget}

\subsection{The Spiral's Shape Modification Process}

In the present work, as explained in the previous section, the spiral shaped antenna printed on a dielectric slab was selected as initial geometry for the design of the RFID tags. The first reason for this selection was the basic attribute of the spiral layout to fill the area it occupies. In this way, a strip antenna with long length would be created and due to this long length, the antenna would be capable of operating at UHF band, without having large size. The second reason comes from the spiral geometry which has several geometrical parameters, as the number and the length of the spiral branches, the distance between them, the width of the printed lines, etc. This fact would potentially help in finding a proper set of parameter values which would lead to an antenna with enhanced performance [21], [22]. Furthermore, the spiral geometry offers two additional advantages. One of them is the easy theoretical calculation which can be preceded for the calculation of the input impedance, the radiated field and the gain, applying a hybrid combination of the Transmission Line Model and the low value of electromotive force induced to the spiral along with the Green function method [21]. The other advantage is that the branches of the spiral can be modified as meandered strip lines [23], or meandered and simultaneously loaded with small patches at the end or along branches [24], [25]. Although these additional modifications increase the number of geometrical parameters making, at a first glance, the antenna design more complicated, actually, in the published works it was proved that it turns to an advantage because offers more degrees of freedom which can be handled via optimization algorithms. In this way, effective tags can be designed [21-25].

As mentioned above and due to the aforementioned reasons, in the present work the spiral shape was selected for the design of the tag antennas. The IC SL3S1203_1213/UCODE G2iL, of sensitivity $-17.6 \mathrm{dBm}$ was selected for the design and fabrication of the tags. As it is well known, there are not mathematical formulas in closed form, which would make easy the design and the modification of the layout of the majority of printed antennas. So, the enhancement of the antenna's performance was approached by a new reconfiguration process of its shape and without any mathematical formulas or any standard optimization technique to be applied. At first, it was supposed that the spiral comes from an open terminated transmission line of two conductors, bent around the input terminals of the line, at which the chip (IC) element is connected conductively (Fig. 1a). Then six modifications of its layout were made. They are divided in two types, in accordance to the target at which they aimed. The modifications of the first type aimed mainly at the matching of the antenna to the IC, namely at the reduction of the signal reflection coefficient value, $\Gamma$, between the antenna and the IC, as it is defined in Sec. 2.2. The modifications of the second type aimed mainly at the configuration of the radiation pattern. However when modifications of one type were being made, e.g. a modification for a desired radiation pattern to be achieved, a check about a low reflection coefficient value was also made, via the simulation, and vice versa. So, the final proposed tag (Fig. 1b) is a result of many repeated reconfigurations of its layout, which substantially were applied in combination, in order to lead to the final tag with the satisfactory performance.

The parameters undergone to modifications of the first type are as follow.

a) The overall length and the number and distances among the branches were changing step by step.

b) The branch line 1 was cut at the position A. The remaining branch lines were bent at the corners.

c) The initial input terminals of the spiral at which the chip 


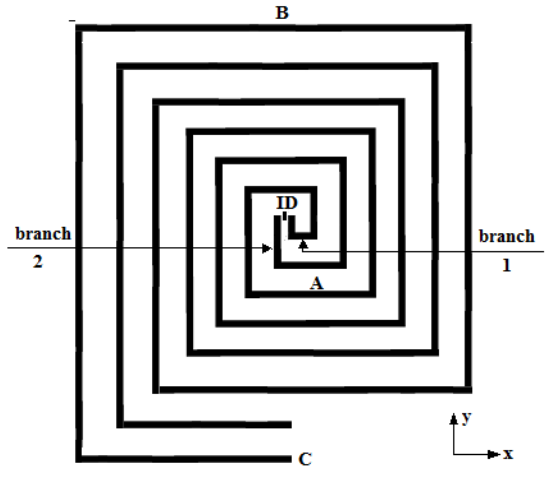

(a)

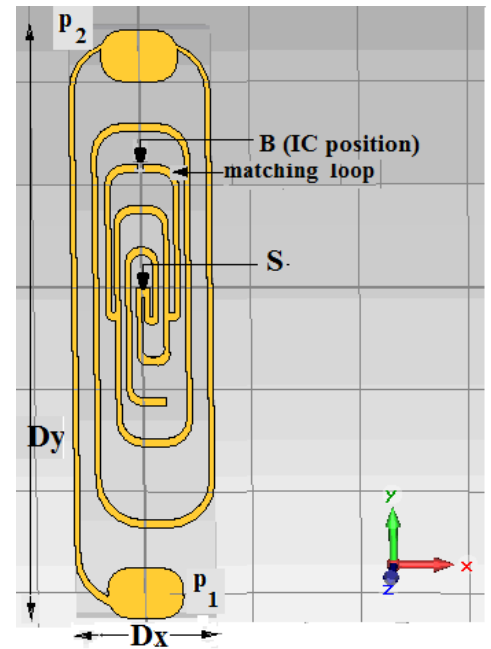

(b)

Fig. 1. The dual-branch spiral shape: a) the initial scheme, b) the final prototype after the modifications (Size: $115 \mathrm{~mm} \times 26 \mathrm{~mm} \times 3.38 \mathrm{~mm}$ ).

would be connected were short-circuited (point S, Fig. 1b). This modification offered the potential to change the position of the chip connection as explained in the next step.

d) A planar printed matching loop was connected to the spiral and the IC was adapted to the loop (point B, Fig. 1b). This loop, in accordance to the theory, increases the inductive imaginary part of the antenna's input impedance and obtains to counterbalance the strongly capacitive input impedance of the IC, which comes from its energy storage stage and is about two to three hundred Ohms. As explained, the position and the size of the loop were found during the process of the repeated layout's modifications and the respective simulation results.

The modifications of the second type were as follows:

a) Scaling of the modified spiral along the $x$ and $y$ directions with different scale factors, at each one, was made. In accordance to the antenna theory, the elongation of an antenna along a specific direction, would make its radiation pattern more narrow on the planes including this direction and simultaneously would increase the gain value. This relation between the width of the main lobe and the gain values of the radiation pattern is an issue that has to be taken into account when an antenna for a specific application is designed. At the proposed antenna the elongation was made along the $y$ direction and the final ratio of the antenna length at the directions $y$ and $x$ was made step by step, the target being the value of the gain to be increased but simultaneously the width of the main lobe of the radiation pattern around the tag to be not very narrow. A very narrow lobe would lead to very high gain but this fact, in the case of the RFID application, would be a disadvantage, because it would increase very much the space area from which and toward which the tag could not effectively receive or transmit signals. The synthesized prototype exhibits a wide space zone, around it, inside which the gain values remain almost constant and high. This fact would enhance the readability of the tag, giving to it the potential to be tracked when having random orientations with respect to the reader's antenna.

b) Small metallic patches with bent corners at the positions $\mathrm{B}$ and $\mathrm{C}$ of branch line 2 were placed. The patches work as two 'islands' of current constituting a two element array along the $y$-direction with distance a little less than $D_{\mathrm{y}}$. Their radiation is added to those of the spiral's currents and due to the arrangement of the two element array along the $y$ axis it enhances the gain of the antenna on the $x z$ plane. On the other hand, the incorporation of the patches in the spiral branches affects the reflection coefficient between the chip and the spiral. So, the total size and the bending of them were found step by step checking simultaneously the radiation pattern, the gain and the reflection coefficient.

\subsection{The Link Budget}

During the process of tag design and in all cases, the criterion of its effective performance was the power that can be ensured at the IC input, which has to be greater than its specified power threshold. The forward link budget can be obtained by using free space Friis equation as [1]

$$
P_{\text {tag }}=P_{\text {EIRPrd }}\left(\frac{\lambda}{4 \pi R_{\text {rd-tag }}}\right)^{2} D_{\text {tag }} e_{\text {tag }}
$$

where $P_{\text {tag }}$ is the available power at the input of the tag antenna, coming from the incident signal, $P_{\text {EIRPrd }}=P_{\mathrm{Trd}} G_{\mathrm{rd}}$ is the effective isotropically radiated power from the reader, $P_{\text {Trd }}$ is the power radiated from the reader, $G_{\text {rd }}$ is the gain of the reader's antenna, $D_{\text {tag }}, e_{\text {tag }}$ are the directivity and the efficiency of the tag antenna, respectively, and $R_{\text {rd-tag }}$ is the distance between the tag and the reader. In the ideal backscattering ASK modulation, the response of the tag switches between the states ' 0 ' and ' 1 '. At the state of ' 1 ' the impedance, seen by the antenna towards the tag, is zeroed via a shorting conductor and the gathered power is totally backscattered. The state of ' 0 ' is the absorbing state at which the backscattered power is minimized, as the IC 
absorbs part of the gathered power, $P_{\operatorname{tag}}[1]$. This absorbed power is

$$
P_{\text {in, chip }}=\left(1-|\Gamma|^{2}\right) P_{\text {tag }} n p
$$

where factors $n$ and $p$ describe the package losses of the IC and the potential polarization mismatching between the reader's and the tag's antennas respectively, $\Gamma=$ $\left(Z_{\text {in,chip }}-Z_{\mathrm{a}}^{*}\right) /\left(Z_{\text {in,chip }}+Z_{\mathrm{a}}\right)$ is the reflection coefficient due to the mismatching, and $Z_{\text {in,chip }}, Z_{\mathrm{a}}$ are, correspondingly, the input impedances of the chip and the antenna. In accordance to the theoretical analysis, the design of the antenna focuses to the achievement of sufficiently high gain level and simultaneously low value of $\Gamma$. In this way, high, as possible, reading distance would be obtained.

In the case of an RFID link, not occurring in absolutely free space, the impact of various scattering mechanisms of the signal in the environment has to be taken into account when $P_{\text {tag }}$ is evaluated. In this work and in order to compare the theoretically expected $P_{\text {in,chip }}$ with the corresponding values received via measurements in Open Area Test Site (OATS), equation (1) was modified as

$$
P_{\text {tag }}^{\mathrm{R} \mathrm{v}, \mathrm{H}}=P_{\text {EIRPrd }}\left(\frac{\lambda}{4 \pi R_{\mathrm{rd}-\mathrm{tag}}}\right)^{2} D_{\mathrm{tag}} e_{\mathrm{tag}} R_{\mathrm{V}, \mathrm{H}}
$$

where by the coefficient $R_{\mathrm{V}, \mathrm{H}}$ (4), the reflection on the ground of OATS for vertically or horizontally polarized propagating signals is taken into account, considering the contribution of only one reflection and not surface waves or secondary effects of the ground [26], [27]

$$
R_{\mathrm{V}, \mathrm{H}}=1+C_{\mathrm{V}, \mathrm{H}} \exp (\mathrm{j} \Delta \varphi) .
$$

In (4), in accordance to the literature, $C_{\mathrm{V}, \mathrm{H}}$ is coefficient depending on the polarization of the wave and the angle of incidence to the ground, as well as the ground's characteristics. Term $\Delta \varphi$, stands for the phase difference between the reflected and the direct path from the transmitting to the receiving antenna, and depends on the height of antennas over the ground, the distance between them and the wavelength. In accordance to the above, equation (2) is generalized to (5)

$$
P_{\text {in, chip }}^{\mathrm{R}_{\mathrm{V}, \mathrm{H}}}=\left(1-|\Gamma|^{2}\right) P_{\mathrm{EIRPPd}}\left(\frac{\lambda}{4 \pi R_{\text {rd-tag }}}\right)^{2} D_{\operatorname{tag}} e_{\text {tag }} R_{\mathrm{V}, \mathrm{H}} n p .
$$

\section{Designed Tags and Results}

\subsection{Tag_DO :Tag for Dielectric Objects}

Starting from spirals of original shape and applying the proposed process, the repeated modifications to their layout provided the tag illustrated in Fig. 1b and the respective photo of the fabricated and measured prototype is presented in Fig. 2a. It is termed as Tag_DO and is the best of the obtained tags.

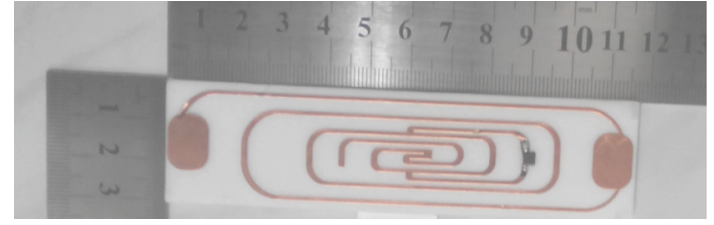

(a) Size: $115 \mathrm{~mm} \times 26 \mathrm{~mm} \times 3.38 \mathrm{~mm}$

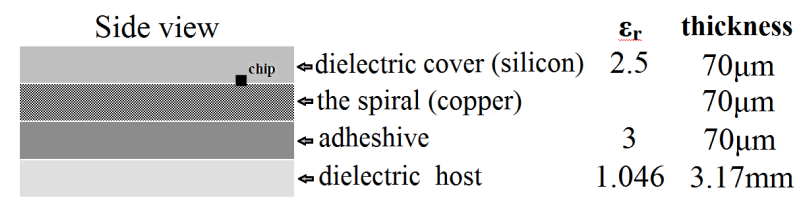

(b)

Fig. 2. Tag_DO : a) The fabricated prototype of the scheme of Fig. 1.b, b) the side view.

In detail, the changes made to the ordinary spiral shape were : a) the layout was changed and the ratio of the lengths of its two sides was made greater than 1 , namely $\left.D_{\mathrm{y}} / D_{\mathrm{x}}=4.42 ; \mathrm{b}\right)$ the initial input terminals of the spiral were short-circuited(point S); c)planar printed matching loop was connected to the spiral and the IC was adapted to this loop (point B); d) two printed metallic patches, $p_{1}$ and $\mathrm{p}_{2}(12.5 \mathrm{~mm} \times 0.94 \mathrm{~mm})$ were incorporated into the spiral at proper positions.

Firstly, the performance of the tag was judged via simulation of its operation and the results are presented in Fig. 3 and 4. In Fig. 3, the real and imaginary parts of the antenna input impedance are illustrated. It is shown that at the frequency of $867 \mathrm{MHz}$ the value of the impedance is $Z_{\mathrm{a}}=(36+\mathrm{j} 220)$ Ohms. This value is close enough to the IC' $\mathrm{s}$ input impedance $Z_{\text {in,chip }}=(25-\mathrm{j} 237) \mathrm{Ohms}$, and yields a satisfactory low reflection coefficient $|\Gamma|=-12.5 \mathrm{~dB}$.

Figure 4 depicts, indicatively, the 3D directivity pattern of the antenna at $867 \mathrm{MHz}$. A wide range with high directive gain around the tag is ascertained and it is in agreement with the respective target of the design. Detailed results for the directivity and the efficiency at the central frequency and at the limits of the frequency band of operation are presented in Tab. 1 and 2

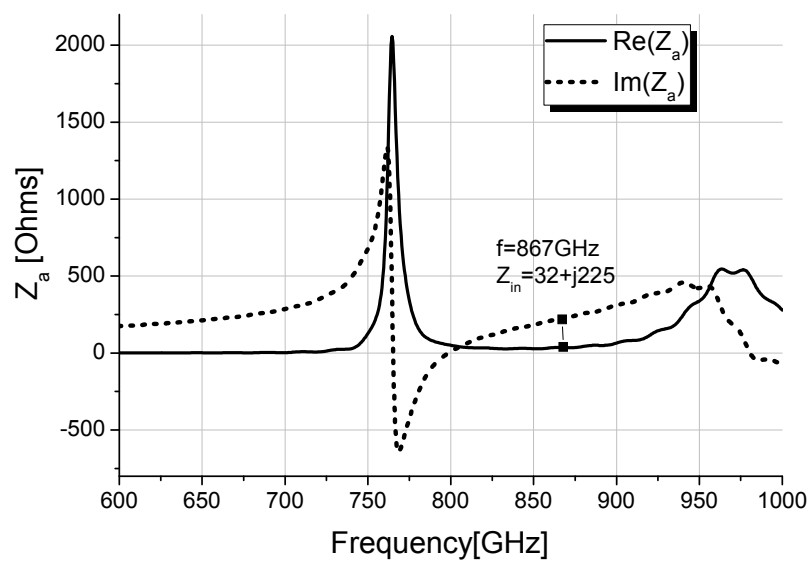

Fig. 3. Tag_DO: Real and imaginary part of the input impedance. 

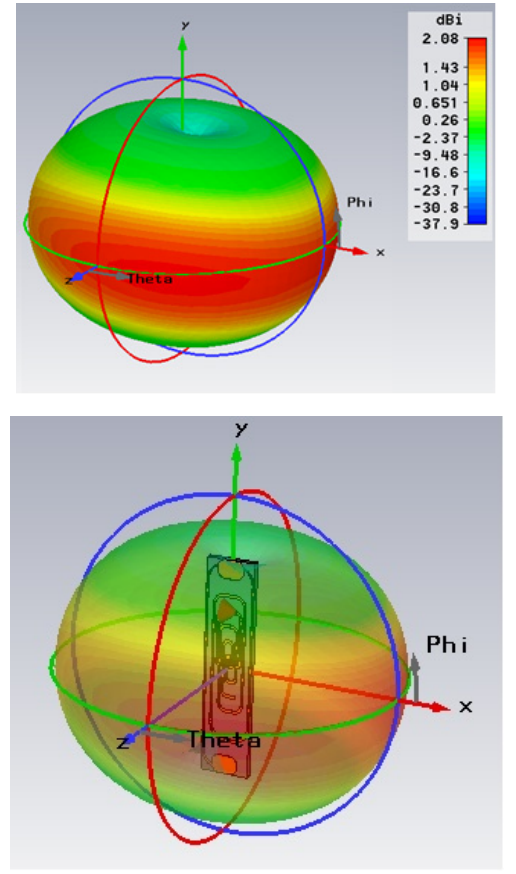

Fig. 4. Tag_DO: 3D directivity pattern of the tag at $867 \mathrm{MHz}$.

\begin{tabular}{|c|c|c|}
\hline Plane & $\boldsymbol{D}_{\max }[\mathbf{d B}]$ & $\boldsymbol{D}_{\min }[\mathbf{d B}]$ \\
\hline$-X Y-$ & 1.94 & -2.26 \\
\hline$-\mathrm{XZ}-$ & 2.075 & -0.938 \\
\hline$-Y Z-$ & 2.02 & -12.21 \\
\hline
\end{tabular}

Tab. 1. Tag_DO: Directivity at $867 \mathrm{MHz}$.

\begin{tabular}{|c|c|c|}
\hline $865 \mathbf{~ M H z}$ & $\mathbf{8 6 7} \mathbf{~ M H z}$ & $\mathbf{8 6 9} \mathbf{~ M H z}$ \\
\hline$-0.4 \mathrm{~dB}$ & $-0.33 \mathrm{~dB}$ & $-0.25 \mathrm{~dB}$ \\
\hline
\end{tabular}

Tab. 2. Tag_DO : Efficiency.

To validate the tag's performance, and so the robustness of the design procedure, the tag was fabricated (Fig. 2a) and measured. The fabricated tag was tested using the reader MTI Wireless Edge/MT-242032/NRH. The reader antenna characteristics were: emitted power $1 \mathrm{~W}$, gain $7 \mathrm{dBi}$, and circular polarization. The measurements were received in OATS (Fig. 5a) at the roof of the building which hosts the laboratory. The floor of the area was covered by aluminum sheet. The tag was positioned in parallel and perpendicularly to the horizontal floor plane(- $x z-$ plane), was rotated around the $-x-,-y-$ and $-z$ - axes and 12 measurements were received at $-y z-,-x z-,-x y$ - planes, respectively. What was checked, was the readability or not of the tag versus its distance from the reader. Figure 6 shows the statistical results by plane and over the total of 36 measurements. The presented results regard to the reading efficiency, namely the number of the times the tag was read over the total times its readability was checked. The rotation of the tag was judged necessary in order a general conclusion to be formed for its efficiency, because in practice, the tag, when attached to the host object, would potentially see the reader, or be shown by it, via a direction different from that of its maximum directivity.

In Fig. 6a it is observed that the reading efficiency varies with the orientation of the tag, reaching to $100 \%$ and holding this portion even at $10 \mathrm{~m}$ away from the reader

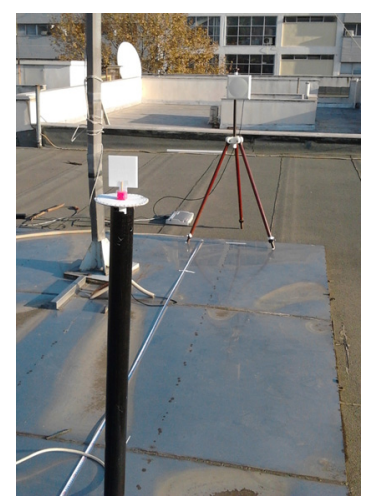

(a)

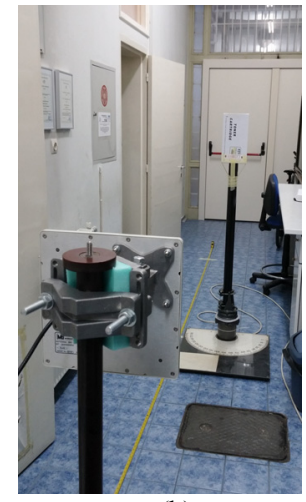

(b)
Fig. 5. a) The OATS at which the measurements of Fig. 6 were received. b) The interior of the laboratory and the experimental arrangement by which the measurements of Fig. 8 were received.

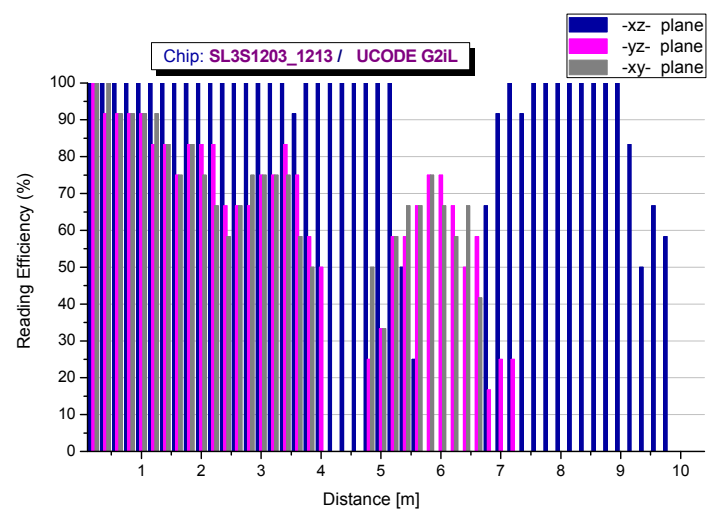

(a)

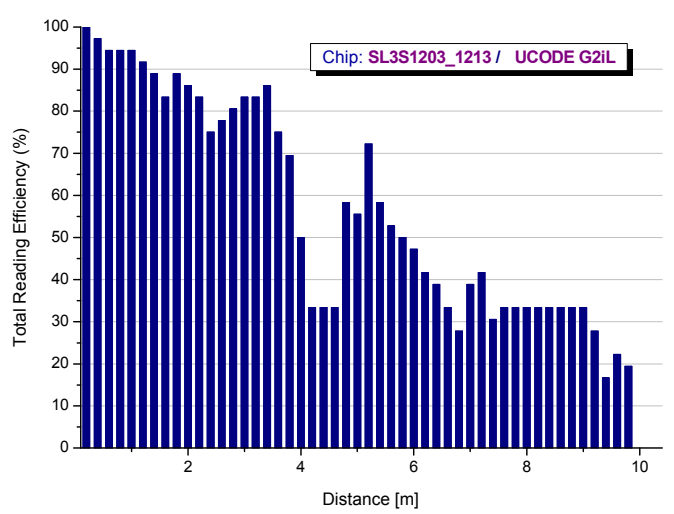

(b)

Fig. 6. Tag_DO: Measured statistical results for the reading efficiency versus the distance from the reader: a) by plane, b) over all three planes.

when the tag is oriented with its large dimension parallel to $-y$ - axis ( $x z$ plane measurements). This axis was considered perpendicular to ground plane of the OATS. Satisfactory results are also obtained when the tag was positioned with its small side perpendicular to the ground ( $y z$ plane measurements). The reading efficiency gets much smaller when the tag is positioned in parallel to the ground. The results give, substantially, information about how the tag would be used. The results of Fig. $6 \mathrm{~b}$ present the reading efficiency over all three orientations of the tag. A noticeable observa- 
tion is that the reading efficiency is minimized at specific distances from the reader, while increases again with further increment of this distance, appearing a local maximum and then tending gradually to zero. It was also observed that the distances of minimization differ from plane to plane. It was estimated that this performance is due to the reflection of the reader's signal at the floor of the OATS. In detail, it is due to the component of the electric intensity of the incident field from which the tag draws energy and also the reflection coefficient for each component, the point of reflection and consequently the distance at which the reflected ray field component cancels the directly propagating one. To validate this estimation, theoretical calculation of the input power of the IC was made via (5). The tag draws power from the vertical or the horizontal component of the reader's incident wave, depending on its orientation. Moreover, its radiation pattern exhibits maximum and minimum directivity per main plain as shown in Tab. 1 . The evaluations were made taking into account these issues. Indicative results are depicted in Fig. 7.

Concisely, Figure 7 depicts the input power to the IC, evaluated by four ways:

a) Graph P1: pure theoretically via 5, taking into account the reflection

b) Graph P2: theoretically but via utilization of measured field values (in presence of reflection). Namely, the electric field intensity was measured via a prototype antenna, at the positions in space, away from the reader, at which the tag was tested. Then, the power resulted from these experimental field values, replaced the terms $P_{\text {EIRPrd }} R_{\mathrm{V}, \mathrm{H}} /\left(4 \pi\left(R_{\mathrm{rd}-\mathrm{tag}}\right)^{2}\right)$ of (5).

c) Graph P3: reduction to free space, of the results of graph $\mathrm{P} 2$ was made, dividing the results presented in this graph by the theoretical reflection coefficients.

d) Graph P4: pure theoretically in free space (2). All the calculations were made using polarization loss factor $p=0.5$, as the fabricated antenna has linear and that of the reader, circular polarization. The IC package loss factor was $n=0.5$.

It was validated that the reading efficiency is in agreement with the theoretical evaluations as at the distances with maximum readability, up to $100 \%$, the input IC power exceeds the IC's sensitivity threshold even if the tag is oriented towards the reader with the direction of its minimum directivity. It happens for distances up to $\sim 5.2 \mathrm{~m}$. Correspondingly, the readability is minimized or zeroed when the tag is positioned at distances at which the reader's signal is minimized, due to the reflection mechanism, and simultaneously the IC's input power is less than its threshold level, even if the tag is oriented to the reader with the direction of its maximum directivity. It is valid between $\sim 5.2 \mathrm{~m}$ to $\sim 6.2 \mathrm{~m}$. At distances from $6.2 \mathrm{~m}$ to $9.5 \mathrm{~m}$ the readability reaches again $100 \%$ as the power input to the chip becomes again greater than its threshold. At these distances perhaps the reflection enhances the reader's signal instead of decreasing it.

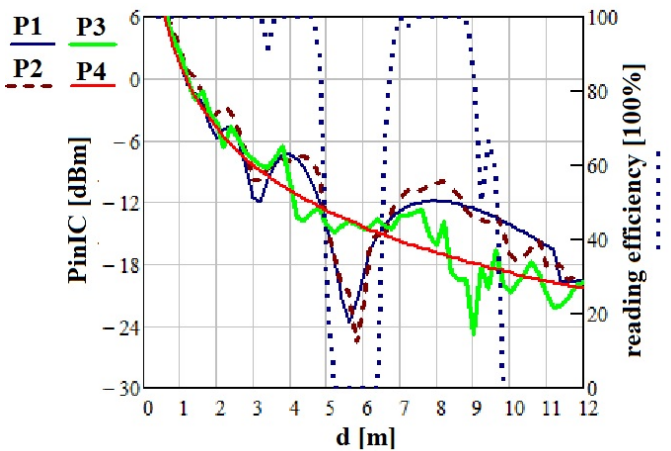

(a)

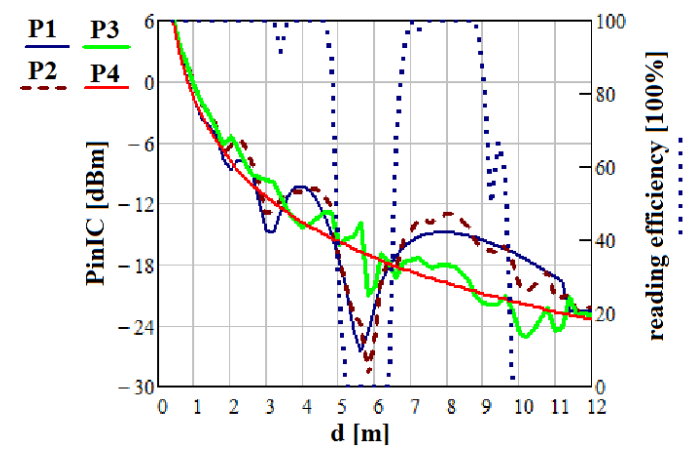

(b)

Fig. 7. Chip input power $[\mathrm{dBm}]$ versus the distance from the reader. Estimation via: (a) the maximum and (b) the minimum gain of the tag antenna. Plotted results: pure theoretical (5) taking into account the reflection (P1), theoretical but via the measured field values (P2), theoretical via the measured field values and by reduction to free space (P3), pure theoretical (2) in free space $(\mathrm{P} 4)$.

The detecting range of the tag is judged very sufficient as it exhibits maximum reading distances comparable or superior to those of several ones, commercial or presented in the literature, with IC of equal sensitivity. Indicatively: a) the tag NXP GP-33[28] of size: $33 \mathrm{~mm} \times 33 \mathrm{~mm} \times 3.38 \mathrm{~mm}$, and the tag DogBone (Monza 4) of the Smartrac Com [29], of size: $86 \mathrm{~mm} \times 24 \mathrm{~mm}$, were measured in OATS (Fig. 5a) and exhibited reading distances $4.7 \mathrm{~m}$ and $9.5 \mathrm{~m}$, respectively. Tags, with size $51 \mathrm{~mm} \times 43 \mathrm{~mm}$, proposed in [8] obtain detection range about $8.6 \mathrm{~m}$. In [10] tags of size $48 \mathrm{~mm} \times 48 \mathrm{~mm}$, exhibit detection range about $6 \mathrm{~m}$. In [18] tags of size $30 \mathrm{~mm} \times 30 \mathrm{~mm}$ have detection range $9.3 \mathrm{~m}$ and in [20] tags of size $10.4 \mathrm{~mm} \times 5.9 \mathrm{~mm} \times 0.76 \mathrm{~mm}$ have the range of $7.3 \mathrm{~m}$.

Beyond the experimental tests in OATS indoor tests, with the tag attached on paper box considered as a dielectric host, were made. The applied procedure was similar to that in OATS and the respective measurements were received in the interior of the laboratory (Fig. 5b). The statistical results of total reading efficiency are presented in Fig. 8. In this case, due to the presence of the paper box, as well as the various mechanisms of signal scattering at the indoor environment, decrease of readability with respect to those in OATS (Fig. 6b) is ascertained. 


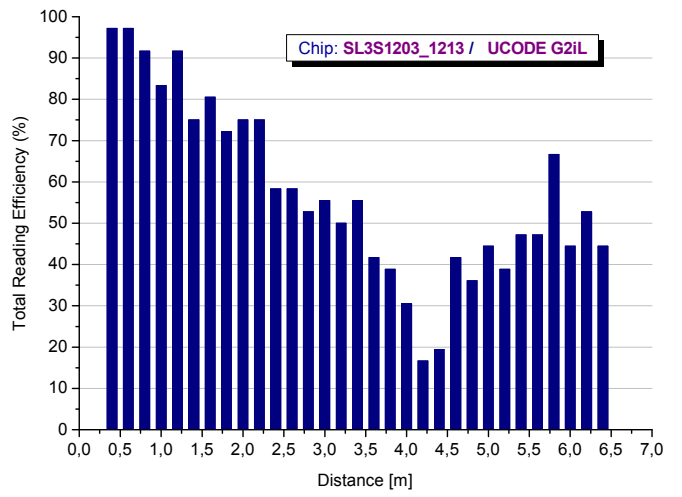

Fig. 8. Tag_DO attached to a paper box including printer toner: Measured statistical results, over all three planes, for the reading efficiency versus the distance from the reader.

\subsection{Tag_MO: Tag for Metallic Objects}

The design of a tag for metallic objects is of increased difficulty as the tag antenna has to meet the requirements of the satisfactory gain level, the proper distribution of the radiated power in the space, the matching to IC and all of them have to be ensured in the presence of a metallic object being in very close proximity to the tag antenna.

The metallic surface of the object due to its electromagnetic behavior, affects strongly the performance of the antenna and this influence increases by the proximity of the antenna to the surface. In the case of the RFID tag, this proximity is the maximum possible as the tag is attached to the object. In the literature, various configurations of antennas destined for metallic hosts have been proposed as, inverted-F type [30], antennas modeled by loop and open and shorted printed strip lines [31], bow-tie patches connected through metallic pins to the back plane [32] or bowtie slot type combined with Artificial Magnetic Conductor (AMC) [33], meander-type [34] or metamaterial structured antennas [35], patches, inset fed by open stub printed line at which the IC is mounted [36], patch antenna with proximity-coupled feed with line shorted at its end [37] and coupled shorted patches fed by printed loop for the IC hosting [38]. The microstrip type is superior to the printed type due to the fact the effectiveness of the printed models are strongly reduced when they are positioned very close to metallic surfaces and moreover large shifting of their resonance frequency occurs. To these disadvantages, the large length of the lines in order to resonate at the UHF RFID band has to be added. A disadvantage of the microstrip type proposed for RFID tags is that satisfactory performance is obtained by incorporating short walls or metallic pins between the radiating element and the ground plane, thus making the fabrication more difficult.

In the present work, for the design of the tag antennas destined for metallic objects, the spiral shape was also adopted along with the modifications made for the design of Tag_DO, except one of them. The spiral shape, as already has been mentioned, has the advantage of large line length but small overall size and moreover shorting pins
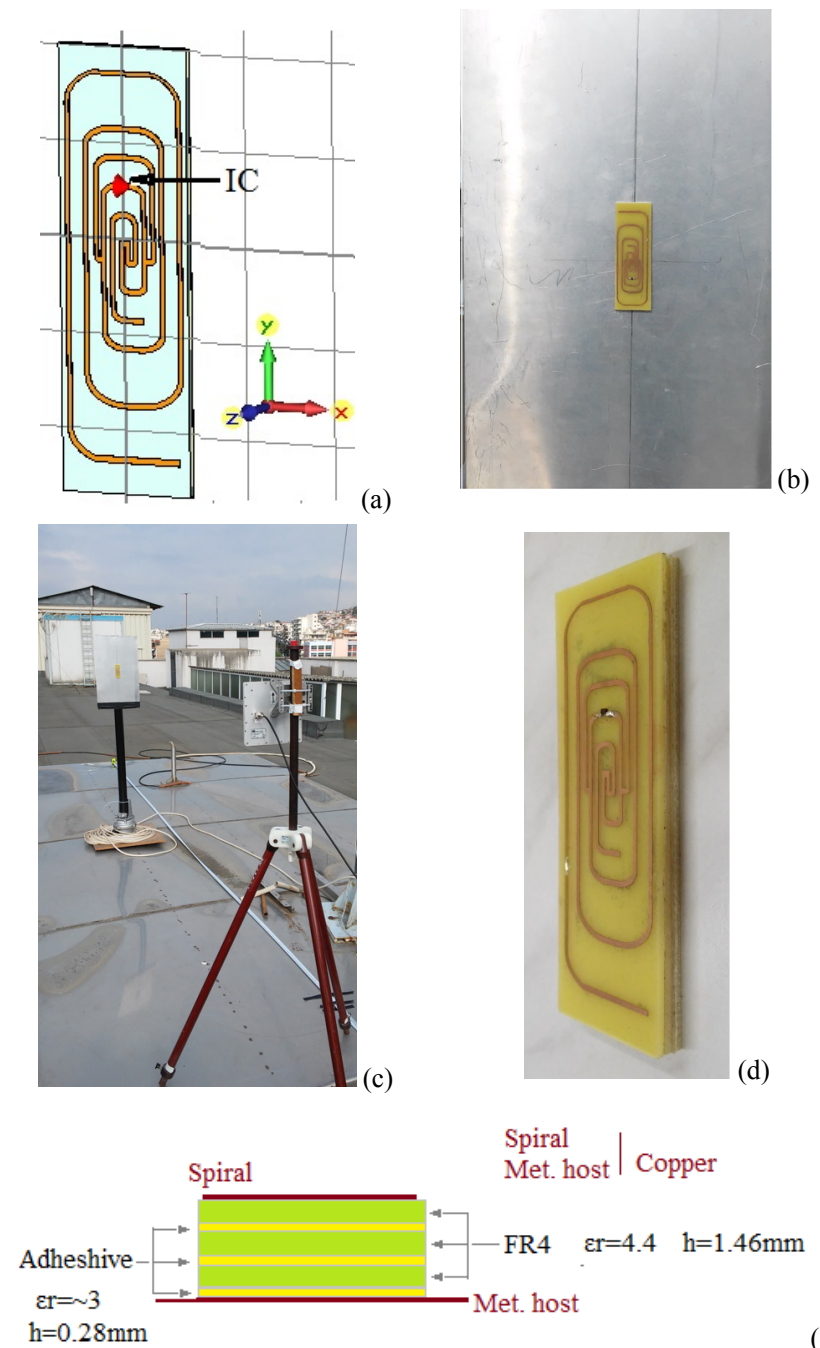

Fig. 9. Tag MO: a) The layout of the tag; b) the tag on a metallic sheet; c) the fabricated prototype on the metallic sheet at the OATS where the measurements of Fig. 11 were received; d) tag's profile and details of its structural parameters.

Size of the tag: $29.32 \mathrm{~mm} \times 94.07 \mathrm{~mm} \times 5.29 \mathrm{~mm}$.

Size of the metallic host: $50 \mathrm{~cm} \times 30 \mathrm{~cm} \times 0.1 \mathrm{~cm}$.

are not necessary. The IC SL3S1203_1213/UCODE G2iL and, as a substrate, the dielectric FR 4 with $\varepsilon_{\mathrm{r}}=4.4$ was also used. The design of the antenna, and also its fabrication, were made using 3 dielectric layers, each one of the thickness of $1.46 \mathrm{~mm}$, and adhesive between them. The three layer substrate keeps the metallic spiral at a distance from the metallic surface greater than that of a single layer and thus its effectiveness is enhanced, however at the cost of a high side profile.

Moreover, at this tag, termed as Tag_MO, printed patches were not incorporated to the spiral because, in contrast to Tag_DO, their presence was degrading the performance of the antenna instead to enhance it, for all the use of three layer dielectric. Perhaps it was due to the trapping of power at the cavities they created with the metallic host. The synthesis and simulation of the antenna was made considering the tag attached to planar thin metallic layer of size $50 \mathrm{~cm} \times 30 \mathrm{~cm} \times 0.1 \mathrm{~cm}$ standing for 


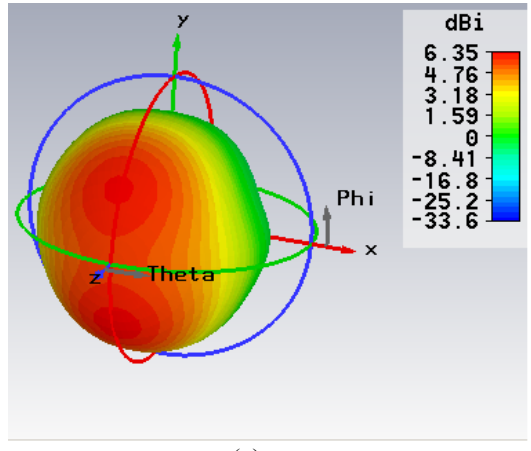

(a)

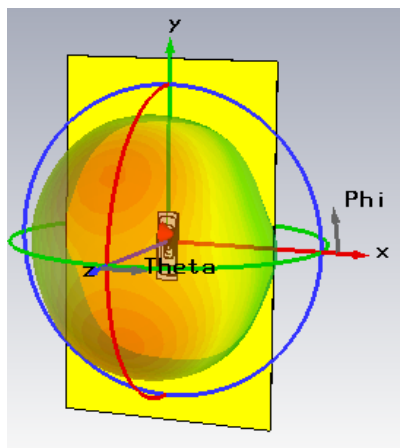

(b)

Farfield Directivity Abs (Phi $=0)$

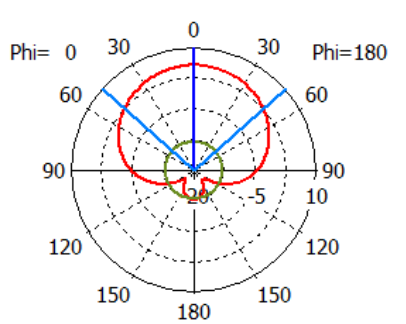

farfield $(f=867)[1]$

Frequency $=867$

Main lobe magnitude $=5.6 \mathrm{dBi}$ Main lobe direction $=0.0 \mathrm{deg}$. Angular width $(3 \mathrm{~dB})=96.8 \mathrm{deg}$

Theta / Dearee vs. dBi (c)

Farfield Directivity Abs (Phi=90)

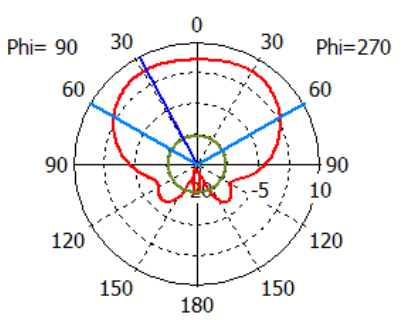

farfield $(f=867)[1]$

Frequency $=867$

Main lobe magnitude $=6.4 \mathrm{dBi}$ Main lobe direction $=28.0 \mathrm{deg}$. Angular width $(3 \mathrm{~dB})=120.3 \mathrm{deg}$.

Theta / Degree vs. dBi

Side lobe level $=-19.1 \mathrm{~dB}$

Fig. 10. Tag_MO: (a) and (b) 3D directivity patterns at $867 \mathrm{MHz}$ received by simulation in the presence of the metallic sheet; (c) and (d) polar directivity patterns on $-x z$ - and $-y z$ - planes respectively.

\begin{tabular}{|c|c|c|}
\hline Plane & $\boldsymbol{D}_{\max }[\mathbf{d B}]$ & $\boldsymbol{D}_{\min }[\mathbf{d B}]$ \\
\hline$-\mathrm{XZ}-$ & 5.59 & -2.82 \\
\hline$-\mathrm{YZ}-$ & 6.36 & -0.9 \\
\hline
\end{tabular}

Tab. 3. Tag_MO: Directivity at $867 \mathrm{MHz}$.

\begin{tabular}{|c|c|c|}
\hline $\mathbf{8 6 5} \mathbf{~ M H z}$ & $\mathbf{8 6 7} \mathbf{~ M H z}$ & $\mathbf{8 6 9} \mathbf{~ M H z}$ \\
\hline$-0.612 \mathrm{~dB}$ & $-0.159 \mathrm{~dB}$ & $-0.4 \mathrm{~dB}$ \\
\hline
\end{tabular}

Tab. 4. Tag_MO: Efficiency.

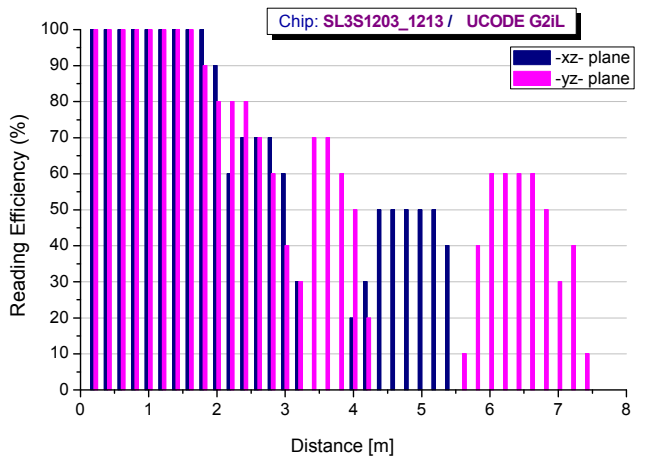

(a)

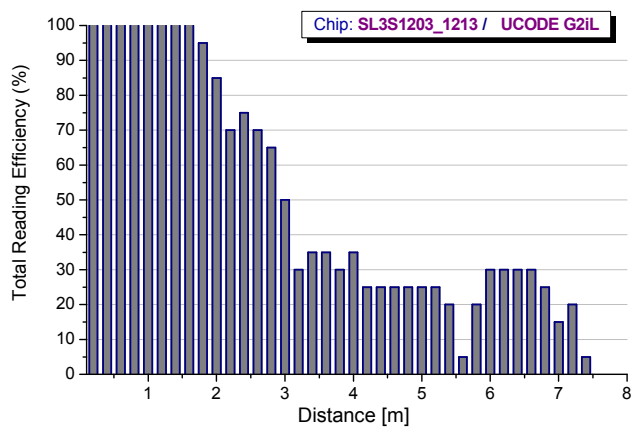

(b)

Fig. 11. Tag__MO: Measured statistical results for the reading efficiency versus the distance from the reader: a) by plane, b) over all three planes.

the metallic host. Details about the geometry and the materials of the tag Tag_MO, as well as the fabricated prototype and the area used for measurements (OATS) are presented in Fig. 9. The OATS was that, used for the measurements of Tag_DO.

From the experimental results, statistically processed and shown Fig. 11a, a satisfactory readability of the Tag_MO is ascertained which reaches the values of $\sim 5.5 \mathrm{~m}$ or $\sim 7.5 \mathrm{~m}$ depending on the orientation of the tag. The distances of minimizations and local maximizations that appear, are different at the two planes, as in the case of Tag_DO. The overall performance (Fig. 11b) is judged as sufficient. The proposed antenna has advantages as a) simple structure compared with other ones with metamaterial [33] or AMC lattices [31], shorting pins [29], [30], [35], [36] etc.; and b) a performance as good as other tags presented in the literature. Indicatively in [19] tags of size $105 \mathrm{~mm} \times 60 \mathrm{~mm} \times 0.76 \mathrm{~mm}$ exhibit reading distance of $7.3 \mathrm{~m}$, in [36] tags of size $111.13 \mathrm{~mm} \times 23.56 \mathrm{~mm}$ have the reading distance of $5 \mathrm{~m}$, in [37] reading distance of $8.9 \mathrm{~m}$ is obtained with tags of size $72.1 \mathrm{~mm} \times 25.5 \mathrm{~mm} \times 3.2 \mathrm{~mm}$ and in [38] tags with size $88 \mathrm{~mm} \times 25 \mathrm{~mm} \times 3.5 \mathrm{~mm}$ have reading distance of $5 \mathrm{~m}$.

\section{Conclusion}

The target of the work was the synthesis of antennas suitable for UHF RFID passive tags with high readability and large reading distances. The spiral shape was selected as the initial antenna geometry and a new approach, con- 
sisting in modification of the spiral layout, was adopted in order that the target to be obtained. The proposed process focused, besides the ordinary matching between the antenna and the IC, to the proper configuration of the antenna radiation patterns. The aim was, the patterns to demonstrate wide space areas, inside which the gain values are high. In this way the readability of the tag would increase as, in practice, the plane of the tag would have various orientations with respect to the reader's antenna. The tags were fabricated and measured and also theoretical results for the link budget in a real environment, taking into account phenomena of reflection, were received. The agreement between theoretical and experimental results is satisfactory. The tag for dielectric objects appears readability even $100 \%$ at distances up to $10 \mathrm{~m}$, when it is properly oriented. The readability reduces for random orientation, however remaining greater than $50 \%$ up to distance of $6 \mathrm{~m}$. The tag designed for metallic hosts has also satisfactory performance demonstrating readability greater than $50 \%$ up to $7 \mathrm{~m}$, when properly oriented. For random orientation, the above value reduces being greater than $30 \%$ up to $7 \mathrm{~m}$.

\section{Acknowledgments}

This research has been co-financed by the European Union (European Social Fund - ESF) and Greek national funds through the Operational Program "Education and Lifelong Learning" of the National Strategic Reference Framework (NSRF) - Research Funding Program: THALES: Reinforcement of the interdisciplinary and/or inter-institutional research and innovation (MIS 377271).

\section{References}

[1] CURTY, J. P., DEClERCQ, M., DEHOLlAin, C., JOEHL, N. Design and Optimization of Passive UHF RFID Systems. Springer, 2007. ISBN: 978-1841270715

[2] BROWN, D. E. RFID Implementation. Mc Graw Hill, 2007. ISBN: 978-0-07-226324-4

[3] RAO, K. V. S., NIKITIN, P. V., LAM, S. F. Antenna design for UHF RFID tags: A review and a practical application. IEEE Transactions on Antennas and Propagation, 2005, vol. 53, no. 12, p. 3870-3876. DOI: 10.1109/TAP.2005.859919

[4] MARROCCO, G. The art of UHF RFID antenna design: Impedance-matching and size-reduction techniques. IEEE Antennas and Propagation Magazine, 2008, vol. 50, no. 1, p. 66 - 79. DOI: 10.1109/MAP.2008.4494504

[5] PANDA, J. R, SALADI, A. S. R, KSHETRIMAYUM, S. R. A compact printed monopole antenna for dual-band RFID and WLAN applications. Radioengineering. 2011, vol. 20, no. 2, p. 464-467.

[6] JANKOWSKI-MIHUŁOWICZ, P., KAWALEC, D., WĘGLARSKI, M. Antenna design for semi-passive UHF RFID transponder with energy harvester. Radioengineering. 2015, vol. 24 , no. 3 , p. $722-728$. DOI: $10.13164 /$ re.2015.0722
[7] MARROCCO, G. Gain-optimized self-resonant meander line antennas for RFID applications. IEEE Antennas and Wireless Propagation Letters, 2003, vol. 2, p. 302-305. DOI: 10.1109/LAWP.2003.822198

[8] ABDULHADI, A. E., ABHARI, R. Dual printed meander monopole antennas for passive UHF RFID tags. In Proceedings of the IEEE International Symposium on Antennas and Propagation. Washington (USA), 2011. p. 988-991. DOI: 10.1109/APS.2011.5996444

[9] RIDA, R. A., YANG, L., BASAT, S. S., FERRER-VIDAL, A., NIKOLAOU, S., TENTZERIS, M. M. Design, development and integration of novel antennas for miniaturized UHF RFID tags. IEEE Transactions on Antennas and Propagation, 2009, vol. 57, no. 11 , p. $3450-3457$. DOI: $10.1109 /$ TAP.2009.2027347

[10] PAREDES, F., ZAMORA, G., HERRAIZ-MARTÍNEZ, F. J., MARTÍN, F., BONACHE, J. Dual-band UHF-RFID tags based on meander-line antennas loaded with spiral resonators. IEEE Antennas and Wireless Propagation Letters, 2011, vol. 10, p. 768-771. DOI: $10.1109 /$ LAWP.2011.2162716

[11] AIVAZIS, E., SIAKAVARA, K., SAHALOS, J. N. Design and analysis of efficient fractal antennas for UHF RFID passive tags. In Proceedings of the 16th European Conference on Antennas and Propagation (EuCAP). Prague (Czech Republic), 2012, p. 3021 to 3025. DOI: 1109/EuCAP.2012.6206102

[12] GHALIBAFAN, J., KASHANI, F. H. A circularly polarized fractal microstrip antenna for RFID applications. In Proceedings of IEEE International Symposium on Radio-Frequency Integration Technology. Singapore, 2009. p. 319-322. DOI: 10.1109/RFIT.2009.5383721

[13] RUSU, M., HIRVONEN, M., RAHIMI, H., ENOKSSON, P., RUSU, C., PESONEN, N., VERMESAN, O., RUSTAD, H. Minkowski fractal microstrip antenna for RFID tags. In Proceedings of the $38^{\text {th }}$ European Microwave Conference (EuMC). Amsterdam (The Netherlands), 2008. p. 666-669. DOI: 10.1109/EUMC.2008.4751540

[14] SUltan, Q. H., SABAAWI, A. M. A. Design a new fractal loop antenna for UHF RFID tags based on a proposed fractal curve. In Proceedings of the 2nd International Conference on Computer Technology and Development (ICCTD). Cairo (Egypt), 2010, p. 6 to 9 . DOI : $10.1109 /$ ICCTD.2010.5646055

[15] MITTRA, R., HOENSCHEL, A. Some novel designs for RFID antennas and their performance enhancement with metamaterials. In IEEE International Workshop on Anti-counterfeiting, Security, Identification. Xiamen (China), 2007. DOI: 10.1109/IWASID.2007.373681

[16] STUPF, M., MITTRA, R., YEO, J., MOSIG, J. R. Some novel design for RFID antennas and their performance enhancement with metamaterials. In Proceedings of the IEEE Antennas and Propagation Society International Symposium. Albuquerque (NM, USA), 2006, p. 1023-1026. DOI: 1109/APS.2006.1710707

[17] KIM, S., KAWAHARA, Y., GEORGIADIS, A., COLADO, A., TENTZERIS, M. M. Low-cost inkjet-printed fully passive RFID tag using metamaterial-inspired antennas for capacitive sensing applications. In Proceedings of the IEEE MTT-S International Microwave Symposium Digest (IMS). 2013. DOI: 10.1109/MWSYM.2013.6697644

[18] ZUFFANElli, S., ZAMORA, G., AGUILA, P., PAREDES, F., MARTIN, F., BONACHE, J. Analysis of the split ring resonator (SRR) antenna applied to passive UHF-RFID design. IEEE Transactions on Antennas and Propagation, 2016, vol. 64, no.3, p. 856-864. DOI : 10.1109/TAP.2015.2513084

[19] SVANDA, M., POLIVKA, M. Stepped impedance coupledpatches tag antennas for platform-tolerant UHF RFID applications. IEEE Transactions on Antennas and Propagation, 2015, vol. 63, no. 9, p. 3791-3797. DOI: 10.1109/TAP.2015.2447034 
[20] SVANDA, M., POLIVKA, M. Matching technique for an on-body low-profile coupled-patches UHF RFID tag and for sensor antennas. IEEE Transactions on Antennas and Propagation, 2015, vol. 63, no. 5, p. 2295-2301. DOI : 10.1109/TAP.2015.2403399

[21] GOUDOS, S. K., SIAKAVARA, K., SAHALOS, J. N. Novel spiral antennas design using swarm intelligence for passive UHF RFID tags. In Proceedings of the 7th European Conference on Antennas and Propagation (EuCAP). Gothenburg (Sweden), 2013. p. 3223-3227.

[22] GOUDOS, S. K., SIAKAVARA, K., SAHALOS, J. N. Novel spiral antenna design using artificial bee colony optimization for UHF RFID applications. IEEE Antennas Wireless Propagation Letters, 2014, vol. 13, p. 528-531. DOI: 10.1109/LAWP.2014.2311653

[23] GOUDOS, S. K., SIAKAVARA, K., SAHALOS, J. N. Modified spiral RFID tag antenna optimal design using artificial bee colony optimization. In Proceedings of the 43rd European Microwave Conference (EuMC). Nuremberg (Germany), 2013, p. 1255-1258. DOI: 10.23919/EuMC.2013.6686892

[24] GOUDOS, S. K., SIAKAVARA, K., SAHALOS, J. N. Design of load-ended spiral antennas for RFID UHF passive tags using improved artificial bee colony algorithm. International Journal of Electronics and Communications (AEU), 2015, vol. 69, no. 1, p. 206-214. DOI: $10.1016 /$ j.aeue.2014.09.008

[25] GOUdOS, S. K., SIAKAVARA, K., THEOPOUlOS, A., VAFIADIS, E. E., SAHALOS, J. N. Application of Gbest-guided artificial bee colony algorithm to passive UHF RFID tag design. International Journal of Microwave and Wireless Technologies, 2016, vol. 8, no. 3, p. 537-545. DOI: $10.1017 /$ S 1759078715000902

[26] JAKES, W. C. Microwave Mobile Communications. John Wiley \& Sons, New York, 1974. ISBN: 0780310691

[27] JANASWAMY, R. Radiowave Propagation and Smart Antennas for Wireless Communications. Kluwer Academic Publishers, 2001. ISBN: 978-1475775105

[28] www.rfidtagworld.com/products/RFID-Tag-Antenna-NXP-UHFManufacturer1241.html

[29] www.smartrac group.com/files/content/Products_Services/PDF/DogBone_M4.pdf

[30] HIRVONEN, M., PURSULA, P., JAAKKOLA, K., LAUKKANEN, K. Planar inverted-F antenna for radio frequency identification. Electronic Letters, 2004, vol. 40, p. 848-850. DOI: 10.1049/el:20045156

[31] LU, J. H., ZHENG, G. T. Planar broadband tag antenna mounted on the metallic material for UHF RFID system. IEEE Antennas and Wireless Propagation Letters, 2011, vol. 10, p. 1405-1408. DOI: 10.1109/LAWP.2011.2178997

[32] LIN, K. H., CHEN, S. L., MITTRA, R. A looped-bowtie RFID tag antenna design for metallic objects. IEEE Transactions on Antennas and Propagation, 2013, vol. 61, no. 2, p. 499-505. DOI: 10.1109/TAP.2012.2224082

[33] HADARIG, R. C., DE COS GOMEZ, M. E., ALVAREZ, Y., LAS-HERAS, F. Novel bow-tie-AMC combination for $5.8 \mathrm{GHz}$ RFID tags usable with metallic objects. IEEE Antennas and Wireless Propagation Letters, 2010, vol. 9, p. 1217-1220. DOI: 10.1109/LAWP.2010.2100358

[34] VISHNUPRIVA, V., ANJU, M., AJU, J, THOMASKUTTY, M. Meander dipole RFID tag for metallic objects. In Proceedings of the $2^{\text {nd }}$ International Conference on Electronics and Communication Systems (ICECS). Coimbatore (India), 2015, p. 1027-1029. DOI: $10.1109 /$ ECS.2015.7124734

[35] UGARTE-MUÑOZ, E., HERRAIZ-MARTÍNEZ, F. J., GONZÁLEZ-POSADAS, V., SEGOVIA-VARGAS, D. Patch antenna based on metamaterials for a RFID transponder, Radioengineering,
2008, vol. 17 , no. 2 , p. 66-71.

[36] MO, L., QIN, CH. Planar UHF RFID tag antenna with open stub feed for metallic objects. IEEE Transactions on Antennas and Propagation, 2010, vol. 58, no. 9, p. 3037-3043. DOI: 10.1109/TAP.2010.2052570

[37] SON, H.-W., JEONG, S.-H. Wideband RFID tag antenna for metallic surfaces using proximity-coupled feed. IEEE Antennas and Wireless Propagation Letters, 2011, vol. 10, p. 377-380. DOI: 10.1109/LAWP.2011.2148151

[38] PENG H. YANG, YAN LI, I, LIJUN JIANG, ET AL. Compact metallic RFID tag antennas with a loop-fed method. IEEE Transactions on Antennas and Propagation, 2011, vol. 59, no. 12, p. 4454-4462. DOI: 10.1109/TAP.2011.2165484

\section{About the Authors ...}

Katherine SIAKAVARA was born in 1954. She received the B.Sc. degree in Physics in 1977 and the M.Sc. degree in Electronics, in 1979, from the Aristotle University of Thessaloniki, Greece. She was awarded the Ph.D. degree in Electrical Engineering from the same university in 1982. She is currently a Professor in the Department of Physics of the University of Thessaloniki, Greece. Dr. Siakavara is author or co-author of 49 international journal papers, 45 papers in proceedings of international conferences, two book chapters in English, and two books in Greek. Her research interests are in the areas of applied electromagnetism, analysis and design of antenna systems, microwaves, and radio-wave propagation and radio-communications.

Sotirios K. GOUDOS was born in 1968. He received the B.Sc. degree in Physics in 1991 and the M.Sc. of Postgraduate Studies in Electronics in 1994, both from the Aristotle University of Thessaloniki. In 2001, he received the Ph.D. degree in Physics from the Aristotle University of Thessaloniki and in 2005 the Master in Information Systems from the University of Macedonia, Greece. In 2011, he obtained the Diploma degree in Electrical and Computer Engineering from the Aristotle University of Thessaloniki. He joined the Department of Physics, Aristotle University of Thessaloniki, in 2013 and is currently an Assistant Professor of the Department. He is author or co-author of more than 90 papers of international scientific journals and conferences and his research interests include antenna and microwave structures design, electromagnetic compatibility of communication systems, evolutionary computation algorithms, and mobile communications.

Argiris THEOPOULOS was born in 1978. He received the B.Sc. degree in Physics in 2005 and the M.Sc. degree in Electronic Physics in 2008 from the Aristotle University of Thessaloniki. He has been working as an Electronics Engineer at Radiocommunications Laboratory of Aristotle University of Thessaloniki since 2013. His main fields of interest are design and development of embedded systems.

John N. SAHALOS was born in 1943. He received his B.Sc. and Ph.D. degrees in Physics. He also received the Diploma (BCE + MCE) in Civil Engineering and the pro- 
fessional Diploma of postgraduate studies in Radio-Electrology. He worked at the ElectroScience Laboratory, the Ohio State University, Columbus, as a Postdoctoral University Fellow. He was a Professor at the University of Thrace and a Professor at the AUTH. Dr. Sahalos is now Professor at the ECE Department of the University of
Nicosia, Cyprus and director of the Radio \& Telecommunications Laboratory (RTeLab). He was a visiting Professor at several universities in USA and Europe. He is the author of four books (three of them in Greek), seven book chapters, and more than 400 articles published in the scientific literature. 